Original article

\title{
Wound healing activity of extract of Gratiola officinalis in vivo
}

\author{
Artyom M. Mylnikov, Dmitry A. Mudrak, Nikita A. Navolokin, Yulia A. Khramova, Alla B. Bucharskaya, \\ Natalya V. Polukonova, Galina N. Maslyakova
}

Saratov State Medical University, Saratov, Russia

Received 16 December 2020, Revised 15 June 2021, Accepted 9 July 2021

(C) 2020, Russian Open Medical Journal

Abstract: Background and aim - Gratiola officinalis extract has antimicrobial properties, but its wound healing activity has not been described.

Material and Methods - The aqueous solution of dry Gratiola officinalis extract was used for treatment of skin wounds with different routes of administration. In the experiment 40 white laboratory male rats with weight of $150 \pm 50$ grams were subjected to the incised model of flat skin wounds in the interscapular region under the general anesthesia. A morphological study was carried out to assess the effectiveness of the therapy administered.

Results - The most effective method of treatment was found to be local application of the extract, which reduced wound healing time by 8 days. Intramuscular and oral administrations reduce healing time by 6 days. Morphological signs of regeneration, which developed under the influence of Gratiola officinalis extract, allowed to estimate the wound healing activity. Clear differentiation and thickness of layers of the newly formed epidermis, a large number of thin-walled vessels and actively proliferating fibroblasts indicate an active regeneration process.

Conclusion - This extract may be interesting to specialists in regenerative medicine as a remedy for treatment of wound processes.

Keywords: flavonoid-containing extract, wound-healing activity, Gratiola officinalis, experimental model, quercetin.

Cite as Mylnikov AM, Mudrak DA, Navolokin NA, Khramova YuA, Bucharskaya AB, Polukonova NV, Maslyakova GN. Wound healing activity of extract of Gratiola officinalis in vivo. Russian Open Medical Journal 2021; 10: e0413.

Correspondence to Artyom M. Mylnikov. Address: Department of Pathological Anatomy, Saratov State Medical University n.a. V.I. Razumovsky, 112, Bolshaya Kazachya str., Saratov, 410012, Russia. E-mail: artyom-mylnikov@mail.ru.

\section{Introduction}

Therapy of the wound process is a topical issue in modern medicine. According to the World Health organization (2017), $20 \%$ of the beds in surgical hospitals are the beds for patients with purulent diseases, and more than $40 \%$ of surgical patients are people with purulent inflammatory diseases and purulent wound complications [1]. Annually, about 5 million patients with purulent and inflammatory soft tissue diseases are registered in the Commonwealth of Independent States, which lead to fatal outcome in $7-11 \%$ of cases. These figures demonstrate the relevance of the problem of purulent infection in surgery. The key task is to find an effective and cost-effective drug with wound healing activity for the treatment of infected wounds [2].

The healing process is largely mediated by cytokines or growth factors, such as the tumor necrosis factor alpha (TNF- $\alpha$ ), transformative growth factor beta (TGF- $\beta$ ), platelet growth factor (PDGF) and vascular endothelial growth factor (VEGF), which promote activation of a number of specialized cells and their migration to the wound site [3-5]. Polymorphonuclear neutrophil leukocytes and macrophages appear around wounds. Macrophages are the main phagocytic cells in the wound process, they provide an effective local antibacterial barrier [6, 7]. Macrophages can induce production of TNF- $\alpha$, TGF $-\beta$, CD68 and other factors [8]. Proliferation of macrophages and epithelioid cells into fibroblasts and angiogenesis are triggered later. The processes of formation and maturation of connective tissue happen at the same time [9]. In this phase fibroblasts synthesize collagen and form new extracellular matrix [10]. Maturation includes the synthesis of extracellular matrix, tissue remodeling, wound contraction. A large number of cytokines and growth factors are involved in wound healing. Their functions are regulated, which reduces the time of wound healing and the risk of undesirable complications [11].

One of the promising areas of research in the treatment of wound processes is the study of wound healing activity of plant extracts. Most of plant extracts have complex chemical composition and therefore they are able to influence the activity of cytokines and growth factors [12]. A promising group of substances with antimicrobial and wound-healing properties are bioflavonoids, which are plant phenolic compounds [13].

In modern scientific literature, there is a direction of research, which are related to the study of wound healing activity of flavonoid-containing plant extracts. For example, the wound healing activity of aqueous extract of leaves and fractions of Ficus exasperata (Moraceae) and its assessment of safety on albino rats has been described [11]. The extract has antibacterial, antiinflammatory, antioxidant, antipyretic effects, which together 
have a direct impact on the wound healing rate [14]. Another example is the study of the effects and mechanisms of action of flavonoids of Blumea balsamifera (L.) DC. on the skin wound in rats. Authors have attempted to prove that the flavonoids of $B$. balsamifera can contribute to the increase of TGF- $\beta$ expression in comparison with the control groups. They also emphasized that TGF- $\beta$ plays a key role in attracting additional inflammatory cells, increasing tissue destruction of macrophages, and facilitating the formation of collagen and granulation tissue [15-17]. The increased expression of TGF- $\beta$ in B. balsamifera groups may be caused by the stimulation of macrophages which is induced by flavonoids in wounds. As earlier studies have shown, macrophages may increase the TGF- $\beta$ content [18].

One of the representatives of the flavonoid-containing extracts is the herbal extract from the Gratiola officinalis L. Different methods of extraction from Gratiola officinalis make it possible to obtain biologically active compositions with various pharmacological effects: laxative, vomiting, antispasmodic, diuretic, digitalis-like effect on the heart, antioxidant, antitumor and immunomodulatory, antipyretic, antimicrobial, antituberculosis [19-21]. The flavonoid containing extract obtained by the authors' method is not toxic and able to positively influence the state of red bone marrow $[22,23]$.

Aim of the study: to evaluate the wound healing effect of flavonoid containing Gratiola officinalis extract and to conduct a comparative analysis of wound healing in cases of topical, oral and intramuscular routes of its application.

\section{Material and Methods}

\section{Extract preparation}

The aqueous solution of the dry extract of Gratiola officinalis was used in the study. We used the material of Gratiola officinalis which was collected in Voskresensky district of Saratov region in the vicinity of the Chardym village in July 2016. Dried leaves of Gratiola officinalis were pre-comminuted for more complete extraction.

The steamed extract of flowers and leaves of the Gratiola officinalis obtained by the patent method (Patent RU 2482863) was non-toxic due to its chemical composition, which had been previously confirmed in rats.

Extract, obtained by this method from the Gratiola officinalis, had the following chemical composition: 4-vinyl-2-methoxyphenol; 2,3-dihydro-3,5-dihydroxy-6-methyl-4H-pyran-4-one; 2,3dihydrobenzofuran; 3-furancarboxylic acid; 5-hydroxymethyl-2formaldehyde; ethyl-a-d-ribozide; 4-propyl phenol; pyrocatechin; L-luxose (pentosa); 6-deoxyhexose L-galactose; ethyl ester benzoyluxic acid; hexadecanic acid (palmitic acid); homovanilic acid; glucose; 1,4-anhydro- d-mannitol; benzoic acid; quercetin. The average value of quercetin in this extract according to the quercetin graduation reference standard $(98 \%)$ Sigma, is $0.66 \%$. Standardization of the extract was carried out by liquid chromatography, the amount of quercetin in the dry residue of extractive substances (derived from $10 \mathrm{~g}$ of dry material Gratiola officinalis) was 350 micrograms [24].

\section{Experimental design (Design of the experiment)}

The experiment was conducted according to "International Guiding Principles for Biomedical Research Involving Animals" [25]. The experiment was carried out in accordance with the guidelines for experimental (preclinical) study of new pharmacological substances and all applicable international, national, and/or institutional guidelines for the care and use of animals were followed. 40 male white laboratory rats weighing $150 \pm 50$ grams were used; the model of flat skin wounds in the interscapular region in rats was reproduced under general anesthesia with the use of the preparation "Zoletil-100" (dissociative anesthetic, permitted in Russia) in the dosage of $15 \mathrm{mg} / \mathrm{kg}$ [26]. The wound was a section of rounded shape with the area of $100 \mathrm{~mm}^{2}$. Epidermis and dermis were dissected up to subcutaneous fatty tissue. It was applied to the interscapular area by cutting out the plane on a pre-prepared stencil. Animals with experimental nonsterile wounds were divided into four groups by a random sampling method of 10 rats in each. The first experimental group contained rats with surface application of the extract to the wound. The second experimental group contained rats with intramuscular injection. Animals with oral injection were included in the third experimental group. All animals in experimental groups were given the extract in the dosage of 1 gram of extract per 1 kilogram of weight by different methods of application. The fourth group was a group of comparison which contained animals with non-sterile wounds, which had been treated daily with $3 \%$ hydrogen peroxide solution. Experiment continued until the wounds finally healed.

\section{Wound area measurement}

The wound healing dynamics was estimated by changing wound area according to the formula: $S=A^{*} B * \pi / 4\left(\mathrm{~mm}^{2}\right)$, where $A$ - width, $B$ - length of the wound in $\mathrm{mm}$. Measurements were made with an electronic caliper once in every two days from the beginning of the experiment. The healing rate of the wound was calculated by the formula $\mathrm{C}=(\mathrm{S} 2-\mathrm{S} 1 / \mathrm{S} 2) * 100 \%$, where $\mathrm{S} 2$ was the initial area of the wound, S1 was the area of the wound on the current day of measurement. When the areas of wounds in experimental animals were determined in each group, we calculated the average area $(M \pm y$, where $M$ was the arithmetic mean, $y$ was the standard deviation of the arithmetic mean). We tallied the percentage of wound area reduction from the initial size (the percentage of wound healing) and the rate of wound healing (the percentage of wound area reduction per day).

\section{Microbiological research}

We took a swab from the wound surface once in every 6 days to assess the microbial dissemination of the wound defect. After that we inoculated the material on the surface of the nutrient agar for the cultivation of microorganisms. The inoculations were incubated for 24 hours at 37 degrees Celsius. The actual quantitative bacterial dissemination (taking into account dilutions and the microbial count in the washing fluid) was estimated by the number of colony-forming units in $1.0 \mathrm{ml}$ of contaminated wash)CFU (colony-forming units) $/ \mathrm{ml}$.

\section{Morphological research}

To compare morphological characteristics of wounds, the rats were subjected to euthanasia sequentially as the wounds healed, but at each stage of the experiment the animals from the each group were subjected to euthanasia. At the end of the experiment, all the rats were euthanized, and samples of the repaired tissue were taken from the wound area for further investigation. One of 
the morphological features that characterizes the degree of activity of reparative and regenerative processes in wound healing was the thickness of the newly formed epidermis. In order to objectify the descriptive characteristics of the epidermis state, morphometric studies were carried out, i.e. the measures of its thickness at two points of the field of view (thickness of the new epidermis, thickness of the epidermis of the wound margins) were obtained from the histological specimen morphometry.

\section{Hematoxylin and eosin (H\&E) staining}

Histological preparations were made according to standard methods. After fixation for 24 hours in $4 \%$ paraformaldehyde, the tissue blocks were dehydrated, embedded in paraffin, and cut into $4-\mu m$-thick sections. The sections were dewaxed and stained with an H\&E staining using standard procedures.

\section{Statistical analysis}

The data was statistically processed using the SPSS 17.0 software. The normal distribution of features was determined by Shapiro-Wilk test. Since the characteristics in the groups were found to be normally distributed, we chose Welch's t-test for estimation of parameters. A difference between mean values with a probability of $95 \%$ (significance level ${ }^{*} p<0.05$ ) by this method was determined at $\mathrm{T} \geq 1.96$.

\section{Results}

\section{Macroscopic view of a wound defect change}

On the 3rd day of the experiment the average area of animal wounds in all groups was quite uniform. In the comparison group the wound area was $379,68 \pm 26,5 \mathrm{~mm}^{2}$, in the group with topical application of Gratiola officinalis extract to the wound it made
$354,55 \pm 31,5 \mathrm{~mm}^{2}$, in groups with intramuscular and oral injections it was $339,7 \pm 42 \mathrm{~mm}^{2}$ and $352,5 \pm 43 \mathrm{~mm}^{2}$ correspondingly.

On the 7th day of the experiment the wounds of the comparison group revealed no hyperemia and edema, they were covered by dry scab and their average area was $297.9 \pm 20.4$. In the experimental groups of animals, the scab exfoliation was observed, and intensive epithelization and hyperemia occurred. Swelling and suppuration of wounds were absent. The average area in the group with topical application of Gratiola officinalis extract was $286 \pm 18.1 \mathrm{~mm}^{2}$, with intramuscular injection $268.9 \pm 36 \mathrm{~mm}^{2}$, with oral injection $-283.3 \pm 28 \mathrm{~mm}^{2}$. These results are shown in Table 1.

From the 11th day of the experiment, there was a significant acceleration of wound healing in the group with intramuscular injection of Gratiola officinalis extract (the share of wound healing was $82.4 \%$ ). In contrast to the comparison group (where the share of wound healing was $51.1 \%$ ) the healing process appeared to be more effective. On the 13th day, we observed the wound healing acceleration in the group with topical application (wound healing rate $-82.3 \%$ ) which, in contrast to the comparison group (wound healing rate - 51.6\%), was $30.7 \%$ more effective. Oral management of Gratiola officinalis extract showed a significant acceleration of healing from the 15th day of the experiment $(84.8 \%)$ in the experimental group versus $57.9 \%$ in the comparison group, which was $25.9 \%$ more effective. These results are shown in Figure 1.

On the 21st day after the operation there was a further reduction in the average area of wounds in all groups of animals: in the comparison group it was $90.5 \pm 3.4 \mathrm{~mm}^{2}$, in the group with topical application of Gratiola officinalis extract it was $1 \pm 0.5 \mathrm{~mm}^{2}$, groups with intramuscular injection and oral injection were measured $1.3 \pm 0.4 \mathrm{~mm}^{2}$ and $9 \pm 4.2 \mathrm{~mm}^{2}$ correspondingly.

Table 1. Dynamics of wound area reduction in rats during treatment with Gratiola officinalis extract

\begin{tabular}{|c|c|c|c|c|c|c|c|c|c|c|c|}
\hline \multirow{2}{*}{$\begin{array}{l}\text { Experimental } \\
\text { group }\end{array}$} & \multirow{2}{*}{ Index } & \multicolumn{10}{|c|}{ Day of experiment } \\
\hline & & 1 & 3 & 5 & 7 & 9 & 11 & 13 & 15 & 17 & 21 \\
\hline \multirow{2}{*}{$\begin{array}{l}\text { Comparison } \\
\text { group }\end{array}$} & S wound $\mathrm{mm}^{2}$ & $413.3 \pm 33.8$ & $379.6 \pm 26.5$ & $361.7 \pm 19.3$ & $297.9 \pm 20.4$ & $279.8 \pm 17.7$ & $202.7 \pm 12.4$ & $200.2 \pm 13$ & $174 \pm 8.9$ & $120.51 \pm 5.6$ & $90.5 \pm 3.4$ \\
\hline & percentage of healing $\%$ & & $8.23 \pm 6.33$ & $12.6 \pm 7.57$ & $28.1 \pm 8.36$ & $32.4 \pm 1.7$ & $51.1 \pm 3.79$ & $51.6 \pm 2.5$ & $57.9 \pm 3.4$ & $70.9 \pm 2.6$ & $78.2 \pm 2.1$ \\
\hline \multirow{3}{*}{$\begin{array}{l}\text { Group of local } \\
\text { application }\end{array}$} & S wound $\mathrm{mm}^{2}$ & $401.8 \pm 32.2$ & $354.5 \pm 31.5$ & $301.6 \pm 18.4$ & $286 \pm 18.1$ & $222.9 \pm 20.3$ & $84.3 \pm 13.6^{*}$ & $71.1 \pm 12^{*}$ & $42.2 \pm 2.3^{*}$ & $12.56 \pm 1.3^{*}$ & $1 \pm 0.5^{*}$ \\
\hline & percentage of healing $\%$ & & $11.7 \pm 2.6$ & $24.9 \pm 6$ & $28.7 \pm 3.2$ & $44.4 \pm 7.8$ & $78.8 \pm 6.5$ & $82.3 \pm 3.7$ & $89.5 \pm 11.3$ & $96.8 \pm 3.9$ & $99.7 \pm 4$ \\
\hline & p-value & 0.218 & 0.562 & 0.682 & 0.721 & 0.473 & 0.008 & $<0.001$ & $<0.001$ & $<0.001$ & $<0.001$ \\
\hline \multirow{3}{*}{$\begin{array}{l}\text { Intramuscular } \\
\text { injection }\end{array}$} & S wound $\mathrm{mm}^{2}$ & $359 \pm 38.4$ & $339.7 \pm 42$ & $302.6 \pm 28.6$ & $268.9 \pm 36$ & $195.5 \pm 24.5$ & $63.6 \pm 8.8^{*}$ & $58.1 \pm 8.7^{*}$ & $54 \pm 9.4^{*}$ & $9.68 \pm 4.4^{*}$ & $1.3 \pm 0.4^{*}$ \\
\hline & percentage of healing $\%$ & & $5.5 \pm 4.4$ & $10.3 \pm 4.8$ & $25.3 \pm 3.2$ & $45.7 \pm 6.3$ & $82.4 \pm 8.9$ & $83.8 \pm 8.3$ & $85 \pm 4.96$ & $97.3 \pm 1.6$ & $99 \pm 1.2$ \\
\hline & p-value & 0.314 & 0.441 & 0.112 & 0.541 & 0.818 & $<0.001$ & $<0.001$ & $<0.001$ & $<0.001$ & $<0.001$ \\
\hline \multirow{3}{*}{ Oral injection } & S wound $\mathrm{mm}^{2}$ & $356.4 \pm 45.6$ & $352.5 \pm 43$ & $320.2 \pm 51$ & $283.3 \pm 28$ & $190.4 \pm 27.3$ & $78.6 \pm 23.8^{*}$ & $72.7 \pm 18.7^{*}$ & $54 \pm 5.13^{*}$ & $37.4 \pm 7.78^{*}$ & $9 \pm 4.2^{*}$ \\
\hline & percentage of healing $\%$ & & $1.5 \pm 3.4$ & $10.16 \pm 4.8$ & $20.7 \pm 3.2$ & $46.6 \pm 6.3$ & $78.3 \pm 8.9$ & $79.7 .8 \pm 8.3$ & $84.8 \pm 4.96$ & $89.6 \pm 1.6$ & $97.4 \pm 1.2$ \\
\hline & $\mathrm{p}$-value & 0.172 & 0.479 & 0.242 & 0.692 & 0.644 & $<0.001$ & $<0.001$ & $<0.001$ & 0.008 & $<0.001$ \\
\hline
\end{tabular}

Data were expressed as mean \pm SEM (standard error mean). ${ }^{*}$ statistically significant differences compared with respective controls (male) was done using Kramer-Welch criterion.

Table 2. Morphometric research of the thickness of the newly formed epidermis and epidermis of the wound margins

\begin{tabular}{|c|c|c|c|}
\hline Experimental group & Index & Value & P-value \\
\hline \multirow{2}{*}{ Comparison group } & Thickness of the new epidermis ( $\mu \mathrm{m})$ & $15 \pm 3$ & \\
\hline & Thickness of the epidermis of the wound margins $(\mu \mathrm{m})$ & $60 \pm 9$ & \\
\hline \multirow{2}{*}{ Group of local application } & Thickness of the new epidermis $(\mu \mathrm{m})$ & $65 \pm 8^{*}$ & $<0.001$ \\
\hline & Thickness of the epidermis of the wound margins $(\mu \mathrm{m})$ & $115 \pm 12 *$ & $<0.001$ \\
\hline \multirow{2}{*}{ Intramuscular injection } & Thickness of the new epidermis $(\mu \mathrm{m})$ & $30 \pm 3^{*}$ & $<0.001$ \\
\hline & Thickness of the epidermis of the wound margins $(\mu \mathrm{m})$ & $76 \pm 8^{*}$ & 0.002 \\
\hline \multirow[b]{2}{*}{ Oral injection } & Thickness of the new epidermis $(\mu \mathrm{m})$ & $36 \pm 2 *$ & $<0.001$ \\
\hline & Thickness of the epidermis of the wound margins $(\mu \mathrm{m})$ & $107 \pm 11^{*}$ & $<0.001$ \\
\hline
\end{tabular}

Data were expressed as mean \pm SEM (standard error mean). * statistically significant differences compared with respective controls (male) was done using Kramer-Welch criterion. 


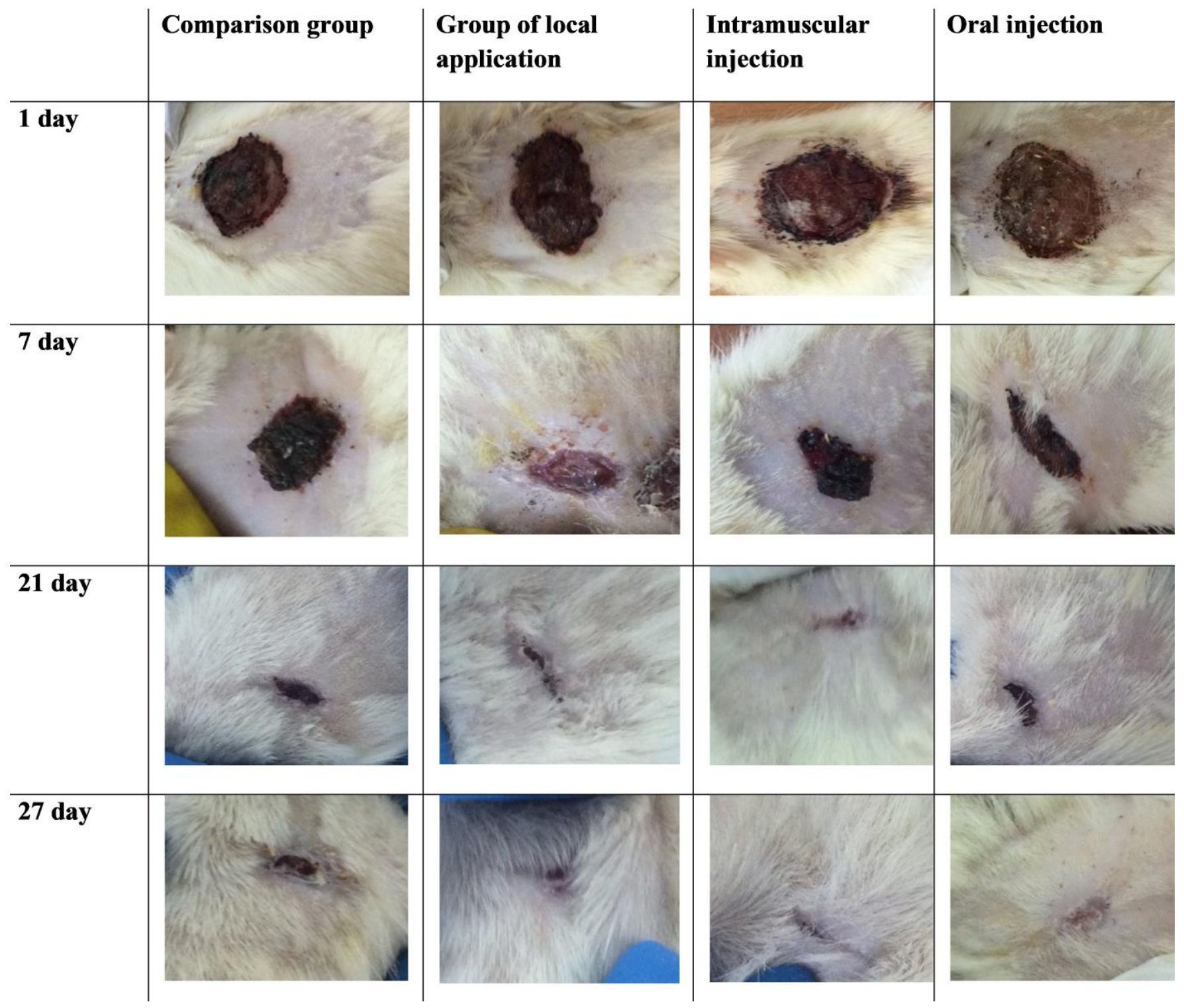

Figure 1. Wound areas in dynamics.

The group with topical application fully completed healing by the 19th day of the experiment. In groups with intramuscular and oral injection of the extract the healing was fully completed within 21 days of the experiment. In the comparison group, full wound healing occurred on the 27 th day of the experiment.

\section{Microbiological screening of a wound defect}

Evaluation of microbiological picture of wounds on the 3rd day of the experiment showed that microbial complications were not observed in the wounds of all groups of animals. On the 9th, 15th, 21st, 27th day after the operation the comparison group of animals revealed massive microbial insemination by bacteria belonging to the $p$. Staphylococcus in the amount of $3.0 \pm 0.05 \mathrm{E} \cdot 10$ $\mathrm{CFU} / \mathrm{ml}$. In the wounds of animals of experimental groups microbial insemination was at the level of $<1.0 \pm 0.05 \mathrm{E} \cdot 10 \mathrm{CFU} / \mathrm{ml}$. These results are shown in Figure 2.

\section{Histological research of a wound defect}

On the 19th day the histological research of skin samples of the wound surface in the comparison group determined the following changes in the epidermis: thinned corneal layer, the lack of clear differentiation of the layers, basal keratinocytes deformed and flattened. Cellular composition of spinous (stratum spinosum) and granular (stratum granulosum) layers was not differentiated. In the papillary layer of the dermis there were a small number of thin-walled blood vessels up to 45 microns in diameter. Most fibroblasts had a spindle shape and elongated hyperchromic nucleus, which indicated the functional inactivity of this cells' subpopulation. The small number of new thin-walled vessels and a large number of functionally inactive fibroblasts indicated a low regenerative potential. Thickness ratio of the newly formed epidermis to the epidermis of the wound margins was 1:4.4. These results are shown in Figure 3A. 
(A) Comparison group

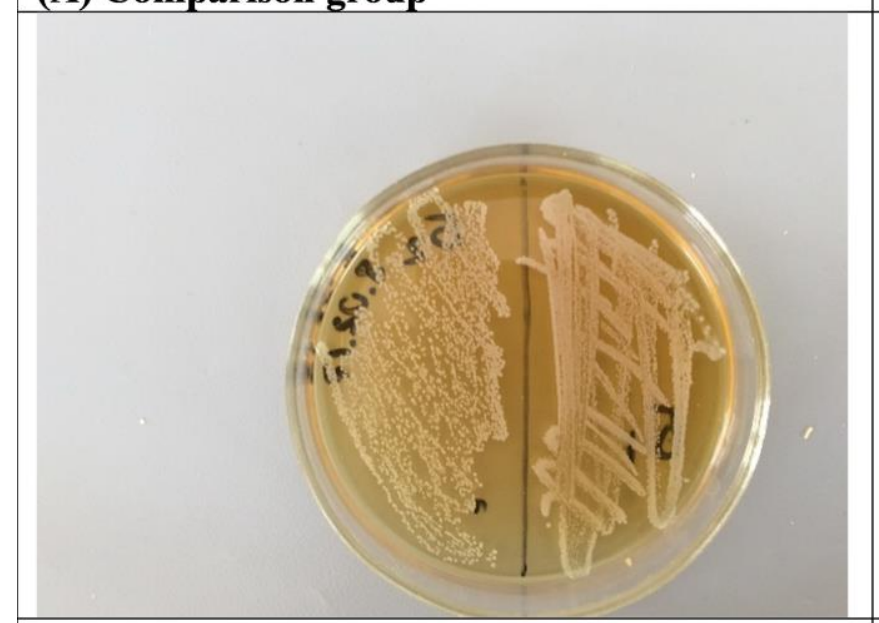

\section{(C) Oral injection}

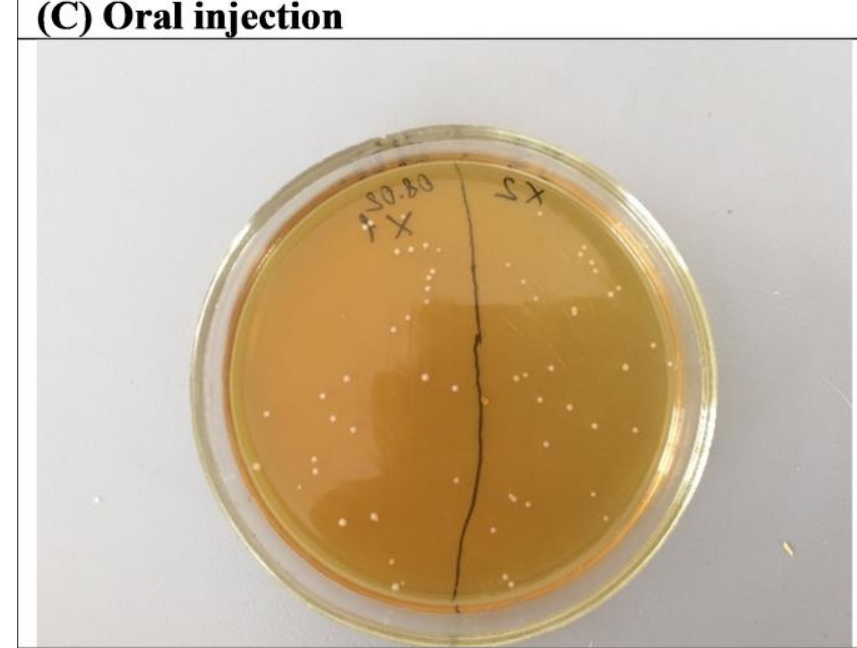

\section{(B) Group of local application}

\section{(D) Intramuscular injection}
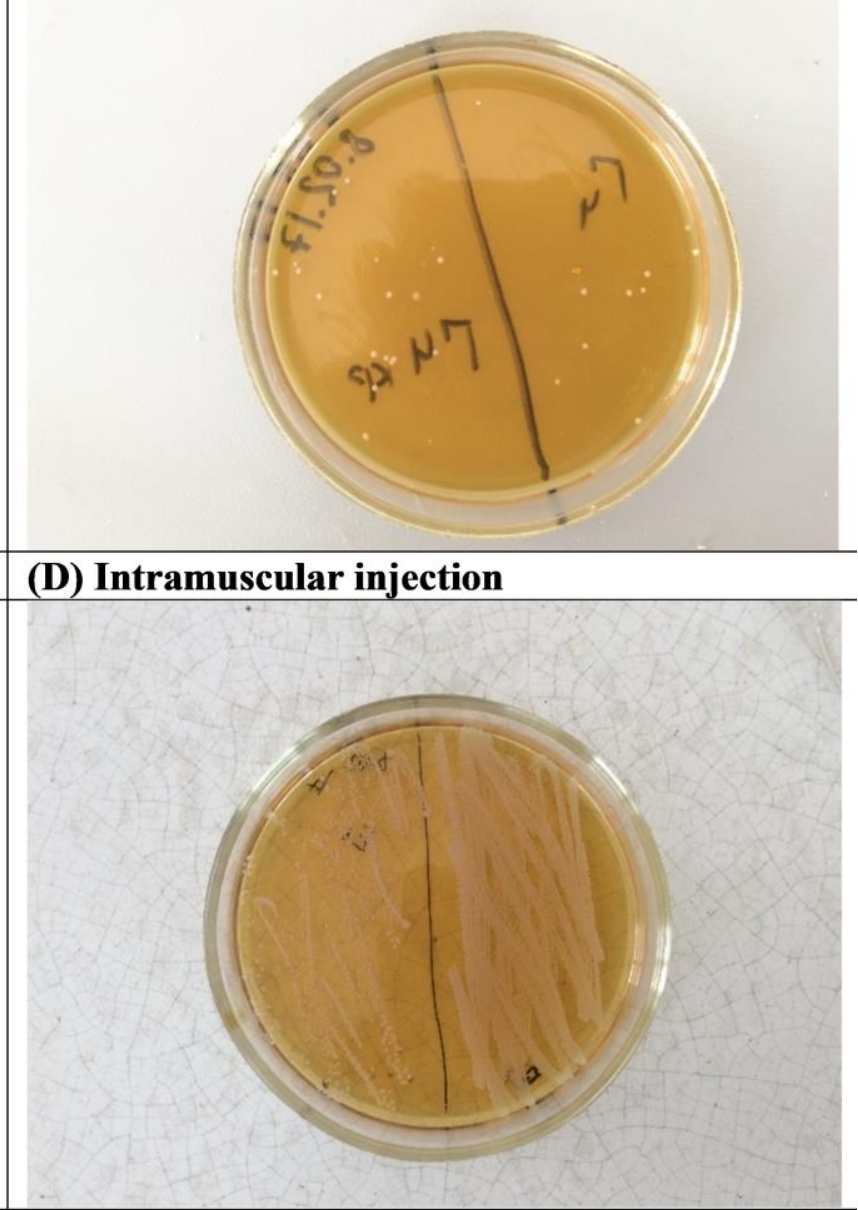

Figure 2. Assessment of microbial contamination of wound defects on the surface of HGM-agar on day 9.

The histological research of skin samples of the wound surface on the 19th day in the group with topical application of Gratiola officinalis extract demonstrated such epidermal changes as thinned horny layer, clear differentiation of the layers, active proliferation of the basal layer's keratinocytes, the presence of a wide spinous layer. In the papillary layer of the dermis there were a large number of thin-walled blood vessels up to 55 microns in diameter, the presence of numerous proliferating fibroblasts and an increased number of macrophages and neutrophils. Thickness ratio of the newly formed epidermis to the epidermis of wound margins was 1:1.9. These results are shown in Figure 3B.

On the 21st day of the experiment, a thinned corneal layer was observed in the comparison group. There was no clearly defined differentiation of the epidermis layers. There were single thinwalled vessels in the papillary layer. A significant number of polygonal shaped proliferating fibroblasts and spindle shaped fibroblasts were observed. Thickness ratio of the newly formed epidermis to the epidermis of wound margins is 1:7.5. These results are shown in Figure $3 \mathrm{C}$.

In the groups of oral and intramuscular injection of Gratiola officinalis extract there was a tendency to layer differentiation and active proliferation of keratinocytes of the basal layer on the 21st day of the experiment. The presence of numerous proliferating fibroblasts and increased number of macrophages, neutrophils and newly formed sebaceous glands were found. Thickness ratio of the newly formed epidermis to the epidermis of the wound margins in case of oral administration was 1:2.2 and in case of intramuscular administration $-1: 2.9$. These results are shown in Figures 3D and 3E.

Morphometric research of the thickness of the newly formed epidermis and the epidermis of the wound margins

As a result of histological morphometry, the parameters of the newly formed epidermis layer and the epidermis layer of the wound margins in all experimental groups exceeded the corresponding parameters of the comparison group. In comparison with the control group, the layer of the newly formed epidermis was 4.3 times thicker for the group with local application, twice thicker for the group with intramuscular administration and 2.4 times thicker for oral administration group. The indexes of epidermal thickness of the wound margins in the experimental groups also exceeded the corresponding indexes in the comparison group as follows: 1.9 higher for local application, 1.3 higher for intramuscular introduction and 1.8 higher for oral introduction. These results are shown in Table 2. 
(A) Comparison group 19 day

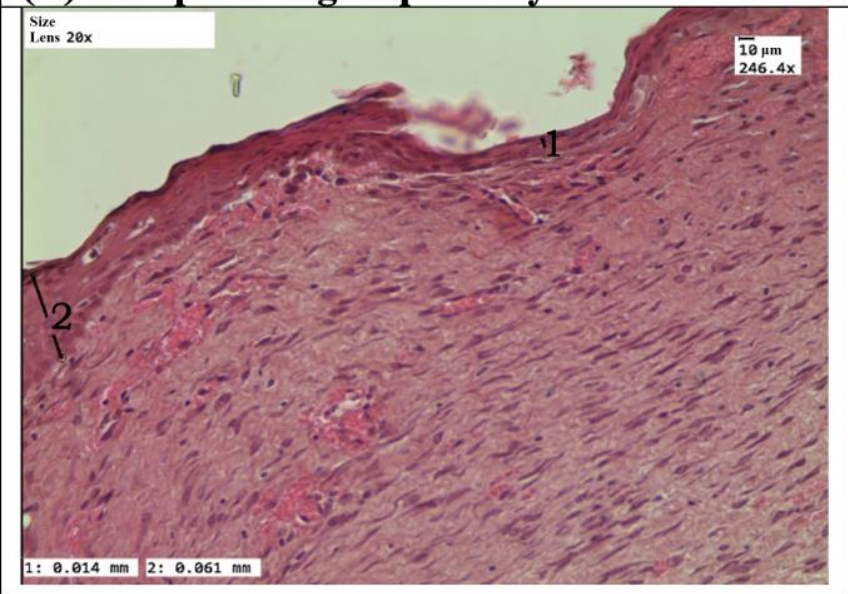

\section{(C) Comparison group 21 day}

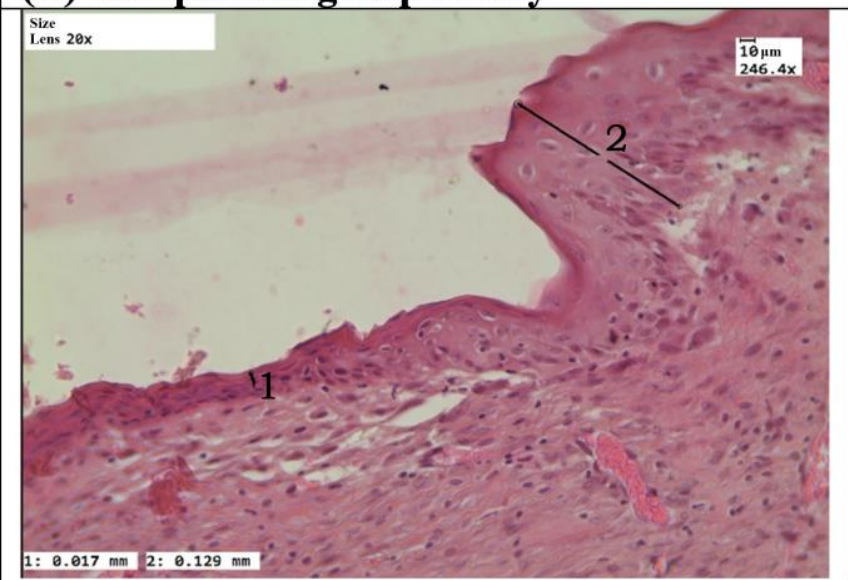

(B) Group of local application 19 day

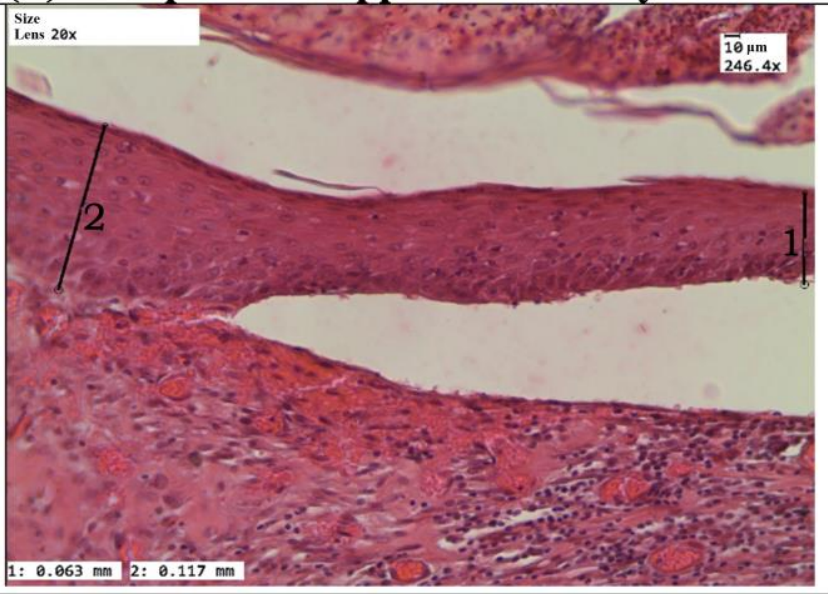

(D) Oral injection 21 day
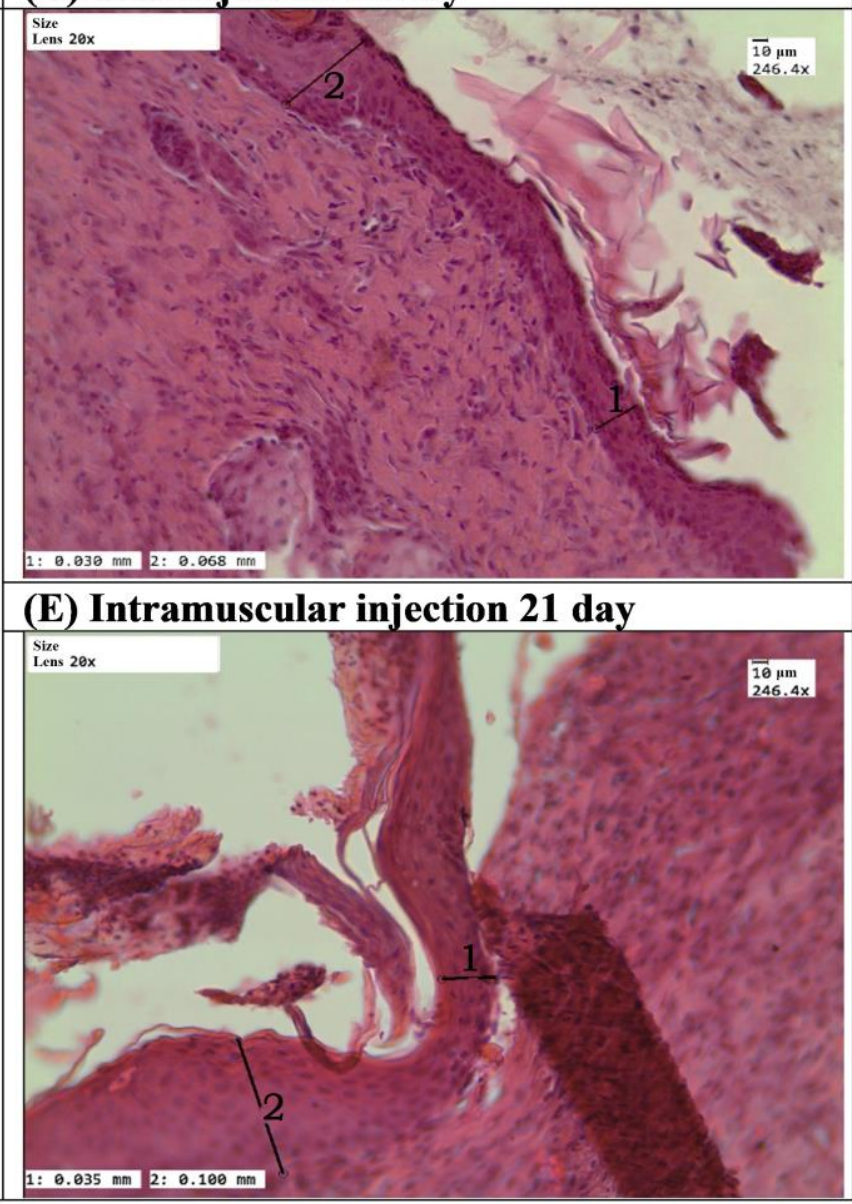

Figure 3. Morphological changes in the comparison group and the experimental group.

\section{Discussion}

Gratiola officinalis extract is a flavonoid containing composition. Flavonoids have a therapeutic application due to their anti-inflammatory, antifungal, antimicrobial, antioxidant and wound healing properties [27-29]. In addition, flavonoids and their derivatives are known to reduce lipid peroxidation, improving blood flow to blood vessels, and preventing or slowing the progression of cell necrosis. Therefore, it is assumed that any drug that inhibits lipid peroxidation increases the viability of collagen fibers by increasing the circulation and strength of collagen fibers, stimulating DNA replication and preventing cell damage [30-32]

When applied topically to the wound, aqueous solution of Gratiola officinalis extract shortens the wound healing time by 8 days in relation to the comparison group. This effect is caused by the direct influence of active components of the extract on the wound defect zone. The bacterial flora was eliminated, which eliminated the possibility of purulent complications. It is known from literature sources that flavonoids are able to activate and 
have a modulating effect on Wnt signaling pathway, which is responsible for the differentiation of stem cells, as well as for the directed attachment of nerves to them. That, in turn, enhances the regenerative activity of tissue and activation of angiogenesis, which was demonstrated in the morphological study of samples of the dissected wound area (a large number of thin-walled vessels, cells of the phagocytic-macrophage system, a large number of proliferating fibroblasts).

In groups with oral and intramuscular administration of Gratiola officinalis extract there was an observation that the wound healing time was 6 days shorter in relation to the comparison group. This time delay, as compared to the group of local application, is due to such a characteristic feature of bioavailability of flavanols as very slow removal of their metabolites from the body (half-life period - from 11 to 28 hours). This may contribute to the accumulation of metabolites in plasma at repeated injection. Quercetin and its metabolites contained in Gratiola officinalis extract are modulators of epidermal growth factor receptors, which stimulate cell growth and cell differentiation of epithelial cover, accelerating the process of early healing [14].

The antimicrobial activity assessment revealed a twofold decrease in microbial semination of wounds in all experimental groups relative to the comparison group. Due to the proven antimicrobial and anti-inflammatory properties, the Gratiola officinalis extract prevents the development of purulent complications of the wound surface [17].

Morphological signs of regeneration, which developed under the influence of Gratiola officinalis extract, revealed at histological examination of wound tissues, allowed the estimation of wound healing activity. Clear differentiation and thickness of layers of the newly formed epidermis, a large number of thin-walled vessels, actively proliferating fibroblasts indicate an active regeneration process. Thickness of the newly formed epidermis at the end of the experiment in all experimental groups more than twice exceeded this morphometric index of the comparison group, which confirms the literature data on the activation of signal pathways responsible for the innervation and differentiation of the epidermis stem cells.

\section{Limitations}

We used 40 white Wistar rats, 10 animals in each group, to study the effect of flavonoid-containing extract of Gratiola officinalis on the process of wound healing. This number represents a sufficient reference sample and allows reliable extrapolation of the study results. All applicable international, national, and/or institutional guidelines for the care and use of animals were followed. The advantages of the proposed new wound healing remedy based on the Gratiola officinalis extract include absence of toxicity, availability of raw materials from which the remedy is obtained and a wide range of other effects: anti-inflammatory, antimicrobial activity, ability to reduce the level of endogenous intoxication. The extract showed efficacy with oral, intramuscular and local application, which is demonstrated by the reduction of wound healing time - the time was reduced by 6 days with oral and intramuscular administration and by 8 days with local application, as well as morphological and morphometric signs of stimulation of tissue regeneration in all experimental groups, compared to the comparison group.

\section{Conclusion}

In summary, the aqueous solution of the dry extract of Gratiola officinalis has wound-healing activity due to the presence of a flavonoid - quercetin, which induces the regenerative potential of tissue. Antimicrobial properties of the extract prevent the development of purulent complications of the wound surface. The most effective route is local application of the product, where wound healing time is reduced by 8 days, intramuscular and oral administrations reduce healing time by 6 days. This extract may be of interest for specialists in the field of regenerative medicine, as an aid in the treatment of wound processes.

\section{Acknowledgment}

This study was supported by Saratov State Medical university, Russia.

Funding

This study was not funded.

\section{Ethical approval}

All applicable international, national, and/or institutional guidelines for the care and use of animals were followed.

\section{Conflict of interest}

The authors declare that they have no conflict of interest.

\section{References}

1. Vinnik YS, Markelova NM, Tyuryumin VS. Modern methods of septic wounds treatment. Siberian Medical Review 2013; (1(79)): 18-24. https://www.elibrary.ru/item.asp?id=20466609.

2. Vardaev LI. Complex treatment of purulent RAS with the use of wound coatings with antioxidant, antibacterial and sorption activity. PhD Dissertation. Moscow, Russia. 2005; 95 p. https://www.elibrary.ru/item.asp?id=16199823.

3. Esser S, Wolburg K, Wolburg H, Breier G, Kurzchalia T, Risau W. Vascular endothelial growth factor induces endothelial fenestrations in vitro. J Cell Biol 1998; 140(4): 947-959. https://doi.org/10.1083/jcb.140.4.947.

4. Ferrara N. Role of vascular endothelial growth factor in regulation of physiological angiogenesis. Am J Physiol Cell Physiol 2001; 280(6): 1358-1366. https://doi.org/10.1152/ajpcell.2001.280.6.C1358.

5. Ashcroft GS, Mills SJ, Ashworth JJ. Ageing and wound healing. Biogerontology 2002; 3(6): 337-345. https://doi.org/10.1023/A:1021399228395.

6. DiPietro LA, Wilgus TA, Koh TJ. Macrophages in Healing Wounds: Paradoxes and Paradigms. Int J Mol Sci 2021; 22(2): 950. https://doi.org/10.3390/ijms22020950.

7. Mantovani A, Sica A, Sozzani S, Allavena P, Vecchi A, Locati M. The chemokine system in diverse forms of macrophage activation and polarization. Trends Immunol 2004; 25(12): 677-686. https://doi.org/10.1016/j.it.2004.09.015.

8. Hameed A, Hruban RH, Gage W, Pettis G, Fox WM 3rd Immunohistochemical expression of CD68 antigen in human peripheral blood T cells. Hum. Pathl 1994; 25(9): 872-876. https://doi.org/10.1016/0046-8177(94)90005-1.

9. Nayak BS, Pinto Pereira LM. Catharanthus roseus flower extract has wound-healing activity in Sprague Dawley rats. BMC Complement Altern Med 2006; 6: 41. https://doi.org/10.1186/1472-6882-6-41.

10. Prockop DJ, Kivirikko KI. Collagens: Molecular biology, diseases, and potentials for therapy. Annu Rev Biochem 1995; 64: 403-434. https://doi.org/10.1146/annurev.bi.64.070195.002155. 
11. Umeh VN, llodigwe EE, Ajaghaku DL, Erhirhie EO, Moke GE, Akah PA. Wound-healing Activity of the Aqueous Leaf Extract and Fractions of Ficus exasperata (Moraceae) and its Safety Evaluation on Albino Rats. J Tradit Complement Med 2014; 4(4): 246-252. https://doi.org/10.1016/j.it.2004.09.015.

12. Smirnova IP, Semkina OA, Bondarenko OV. Plant extracts in development of medicinal products of various therapeutic value. Antibiotics and Chemotherapy 2016; 61(3-4):30-34. https://www.elibrary.ru/item.asp?id=26276898.

13. Mullagulov RT, Kozlov VN, Ponomareva LF. Study of antioxidant activity of medicinal herbs by chemiluminescence in experiments in vitro. Vestnik of Volzhsky University after V.N. Tatischev 2012; (1(9)): 231-234. https://www.elibrary.ru/item.asp?id=17735678.

14. Manjunatha BK, Vidya SM, Rashmi KV, Mankani KL, Shilpa HJ, Jagadeesh Singh SD. Evaluation of wound healing potency of Vernonia arborea Hk. Indian J Pharmacol 2005; 37(4): 223-226. https://doi.org/10.4103/0253-7613.16567.

15. Lim JS, Yoo G. Effect of fat stromal cells and their extract on wound healing in a mouse model. J Korean Med Sci 2010; 25(5): 746-751. https://doi.org/10.3346/jkms.2010.25.5.746.

16. Greenwel $\mathrm{P}$, Inagaki $\mathrm{Yu}, \mathrm{Hu} \mathrm{W}$, Walsh M, Ramirez F. Sp1 is necessary for early response of $\alpha 2$ (I) collagen to transformative growth factorß1. J Biol Chem 1997; 272(32): 19738-19745. https://doi.org/10.1074/jbc.272.32.19738.

17. Mauviel A, Chung KY, Agarwal A, Tamai K, Uitto J. The cell-specific induction of individual oncogens of the Jun family is responsible for differential regulation of collagenase gene expression by transformation of growth factor- $\beta$ in fibroblasts and keratinocytes. J Biol Chem 1996; 271(18): 10917-10923. https://doi.org/10.1074/ibc.271.18.10917.

18. Li XF, Wang hJ, Luo $\mathrm{H}$. Tenporal relationship of transforming growth factor- $\beta$ mRNA with the healing process of mouse skin wounds. Nan Fang Yi Ke Da Xue Xue Bao 2006; 26(1): 59-61. Chinese. https://pubmed.ncbi.nlm.nih.gov/16495177.

19. Polukonova NV, Navolokin NA, Răkova SV, Masliakova GN, Bucharskaia AB, Durnova NA, Shub GM. Anti-inflammatory, antipyretic and antimicrobial activity of flavonoid-containing extract of Gratiola officinalis L. Eksp Klin Farmakol 2015; 78(1): 34-38. https://pubmed.ncbi.nlm.nih.gov/25826873.

20. Navolokin NA. Effect of extracts of Gratiola officinalis and Zea mays on the tumor and the morphology of the internal organs of rats with transplanted liver cancer. Russ Open Med J 2012; 1: 0203. https://www.elibrary.ru/item.asp?id=17949367.

21. Navolokin NA, Skvortsova VV, Polukonova NV, Manaenkova EV, Pankratova LE, Kurchatova MN, et al. Antituberculous in vitro activity of Gratiola officinalis extract. Experimental and Clinical Pharmacology 2015; 78(4): 10-13. https://doi.org/10.30906/0869-2092-2015-78-410-13.

22. Tkachenko N, Pravdin A, Terentyuk G, Navolokin N, Kurchatova M, Polukonova N. Inhibiton of photodynamic haemolysis by Gratiola officinalis L. Extract. In: Progress in biomedical optics and imaging Proceedings of SPIE 9448, Saratov Fall Meeting 2014: Optical Technologies in Biophysics and Medicine XVI; Laser Physics and Photonics XVI; and Computational Biophysics, 94480P. 2015; 9448. https://doi.org/10.1117/12.2179862.

23. Navolokin NA, Mudrak DA, Bucharskaya AB, Matveeva OV, Tychina SA, Polukonova NV, et al. Effect of flavonoid-containing extracts on the growth of transplanted sarcoma 45, peripheral blood and bone marrow condition after oral and intramuscular administration in rats. Russ Open Med J 2017; 6: e0304. https://doi.org/10.15275/rusomj.2017.0304.

24. Polukonova NV, Kurchatova MN, Navolokin NA, Bucharskaya AB, Durnova NA, Maslyakova GN. A new extraction method of bioflavonoids from poisonous plants (Gratiola Officinalis L.). Russ Open Med J 2014; 3: 0304. https://doi.org/10.15275/rusomj.2014.0304
25. International guiding principles for biomedical research involving animals. CIOMS-ICLAS. 2012; 4 https://grants.nih.gov/grants/olaw/Guiding_Principles_2012.pdf.

26. Mironov AN, Ed. Guidelines for conducting preclinical drug trials. Part One. Moscow: Grif and K. 2013; 944 p. https://www.regmed.ru/Content/Page.aspx?id=30e5e2b2-74a6-46169624-b796f00d0a9b.

27. Nayak BS, Sandiford S, Maxwell A. Evaluation of the wound-healing activity of ethanolic extract of Morinda citrifolia L. leaf. Evid Based Complement Alternat Med 2009; 6(3): 351-356. https://doi.org/10.1093/ecam/nem127.

28. Zuanazzi JAS, Montanha JA. Flavonóide. In: Farmacognosia: da planta ao medicamento. 5th ed. Porto Alegre: Ed. da UFRGS; Florianópolis: Ed. da UFSC. 2004: 577-614. Portuguese. https://www.worldcat.org/title/farmacognosia-da-planta-aomedicamento/oclc/709405078?referer=di\&ht=edition

29. Santos SC, Mello JCP. Taninos. In: Simões CMO, Ed. Farmacognosia da Planta ao Medicamento. 6th ed. Porto Alegre: Editora da Universidade Federal do Rio Grande do Sul. 2007: 615-656.

30. Okuda T. Systematics and health effects of chemically distinct tannins in medicinal plants. Phytochemistry 2005; 66(17): 2012-2031. https://doi.org/10.1016/j.phytochem.2005.04.023.

31. Getie M, Gebre-Mariam T, Rietz R, Neubert RH. Evaluation of the release profiles of flavonoids from topical formulations of the crude extract of the leaves of Dodonea viscosa (Sapindaceae). Pharmazie 2002; 57(5): 320-322. https://pubmed.ncbi.nlm.nih.gov/12061256.

32. Shetty S, Udupa S, Udupa L. Evaluation of antioxidant and wound healing effects of alcoholic and aqueous extract of Ocimum sanctum Linn in rats. Evid Based Complement Alternat Med 2008; 5(1): 95-101. https://doi.org/10.1093/ecam/nem004.

\section{Authors:}

Artyom M. Mylnikov - PhD student, Pathological Anatomy Department, Saratov State Medical University, Saratov, Russia. https://orcid.org/00000003-2433-8228.

Dmitry A. Mudrak - PhD student, Pathological Anatomy Department, Saratov State Medical University, Saratov, Russia. https://orcid.org/00000001-7399-9204.

Nikita A. Navolokin - PhD, Assistant Professor, Pathological Anatomy Department, Saratov State Medical University, Saratov, Russia. https://orcid.org/0000-0001-7876-9758.

Yulia A. Khramova - PhD, Assistant Professor, Department of Foreign Languages, Saratov State Medical University, Saratov, Russia. https://orcid.org/0000-0003-2870-8361.

Alla B. Bucharskaya - PhD, Director of the Center for Shared Use of the Research Institute of Fundamental and Clinical Uronephrology, Saratov State Medical University, Saratov, Russia. https://orcid.org/0000-00030503-6486.

Natalya V. Polukonova - PhD, Professor, Department of Biology, Saratov State Medical University, Saratov, Russia https://orcid.org/0000-00019228-6808.

Galina N. Maslyakova - MD, DSc, Professor, Pathological Anatomy Department, Saratov State Medical University, Saratov, Russia https://orcid.org/0000-0001-8834-1536. 